\title{
Bone Histology of Two Cases with Osteomalacia Related to Low-dose Adefovir
}

\author{
Rikako Hiramatsu ${ }^{1}$, Yoshifumi Ubara ${ }^{1,2}$, Naoki Sawa ${ }^{1}$, Eiko Hasegawa ${ }^{1}$, Masahiro Kawada ${ }^{1}$, \\ Aya Imafuku ${ }^{1}$, Keiichi Sumida ${ }^{1}$, Junichi Hoshino ${ }^{1}$ and Kenmei Takaichi ${ }^{1,2}$
}

\begin{abstract}
We performed a bone histomorphometric analysis in two patients demonstrating Fanconi syndrome with hypophosphatemia, adefovir-related bone disease and chronic hepatitis B infection. Both patients had osteomalacia, but showed two different histological patterns. The osteoid volume of the patient without risedronate increased with [(osteoid volume/ bone volume $) \times 100=18.6 \%]$. However, the osteoid volume of the patient receiving risedronate without vitamin D analogue showed a greater increase of 53.8\%. In both patients bone pain and hypophosphatemia subsided soon after the discontinuation of adefovir and the administration of phosphate derivative. These findings show that bisphosphonate may worsen this disease when this drug is administered without a vitamin D analogue.
\end{abstract}

Key words: adefovir-related bone disease, osteomalacia, chronic hepatitis B infection, risedronate

(Intern Med 55: 3013-3019, 2016)

(DOI: 10.2169/internalmedicine.55.6806)

\section{Introduction}

Adefovir dipivoxil (ADV) is used to treat (chronic) infection associated with hepatitis B virus (HBV). It acts by blocking reverse transcriptase, an enzyme that is crucial for the spread of HBV. However, Fanconi syndrome and bone disease have been reported to occur even in patients taking a low daily dose of ADV (10 mg). In 2010, Wong et al. reported a 40-year-old man in whom Fanconi syndrome and bone disease occurred after ADV was administered at $10 \mathrm{mg}$ daily for chronic hepatitis B infection, and whose bone pain improved after the cessation of ADV and the administration of phosphate supplementation. His bone disease was clinically diagnosed as adefovir-related osteomalacia, based on symptoms of widespread bone pain and the detection of microfractures by magnetic resonance imaging (1). Similar cases have also been reported by Girgis and Kim in 2011 and 2012, respectively $(2,3)$. Since a close relation between Fanconi syndrome and osteomalacia has been histologically demonstrated in previous studies (4), adefovir-related bone disease has been diagnosed to be osteomalacia based only on the clinical features without examining the bone histol- ogy, even though osteomalacia requires a histological diagnosis (1-3).

We encountered two patients with chronic hepatitis B infection in whom adefovir-related bone disease was diagnosed to be osteomalacia based on bone histomorphometry. We found that one patient had been treated with a secondgeneration bisphosphonate (BP) (risedronate) to treat bone pain by another doctor. The histological changes of the bone in Adefovir-related osteomalacia with or without risedronate treatment are herein described and discussed.

\section{Case Reports}

\section{Case 1}

In August 2012, a 67-year-old Japanese woman was admitted to our hospital for an evaluation of severe pain in the bilateral ankles to distal tibiae, knee joints, and ribs. Hepatitis due to HBV infection was diagnosed in 1983. Lamivudine was started in 2006, but her hepatitis did not subside, so low-dose ADV was added (10 mg daily) in March 2008. Two months later, the HBV-DNA polymerase titer became negative. In June 2012, generalized bone pain sud-

${ }^{1}$ Nephrology Center, Toranomon Hospital, Japan and ${ }^{2}$ Okinaka Memorial Institute for Medical Research, Toranomon Hospital, Japan Received for publication November 7, 2015; Accepted for publication February 24, 2016

Correspondence to Dr. Yoshifumi Ubara, ubara@toranomon.gr.jp 
Table 1. Laboratory Test.

\begin{tabular}{|c|c|c|c|}
\hline Laboratory test & normal range & case 1 & case 2 \\
\hline \multicolumn{4}{|l|}{$\begin{array}{r}\text { Serum } \\
\end{array}$} \\
\hline Asparate aminotransferase & $13-33(\mathrm{IU} / \mathrm{L})$ & 24 & 16 \\
\hline Alanine aminotransferase & 6-27( IU/L) & 11 & 13 \\
\hline Alkaline phosphatase & $117-350(\mathrm{IU} / \mathrm{L})$ & 819 & 961 \\
\hline Total protein & $6.9-8.4(\mathrm{mg} / \mathrm{dL})$ & 5.8 & 7.5 \\
\hline Albumine & $3.9-5.2(\mathrm{mg} / \mathrm{dL})$ & 2.5 & 3.6 \\
\hline Uric nitrogen & $8-21(\mathrm{mg} / \mathrm{dL})$ & 16 & 17 \\
\hline Creatinine & $0.4-0.8(\mathrm{mg} / \mathrm{dL})$ & 0.6 & 0.8 \\
\hline Uric acid & $2.5-7.0(\mathrm{mg} / \mathrm{dL})$ & 1.3 & 1.2 \\
\hline Sodium & $139-146(\mathrm{mmol} / \mathrm{L})$ & 147 & 145 \\
\hline Pottasium & $3.7-4.8(\mathrm{mmol} / \mathrm{L})$ & 3.2 & 4 \\
\hline Chloride & $101-109(\mathrm{mmol} / \mathrm{L})$ & 119 & 112 \\
\hline Calcium & $8.7-10.1(\mathrm{mg} / \mathrm{dL})$ & 8.1 & 9 \\
\hline Phosphate & $2.8-4.6(\mathrm{mg} / \mathrm{dL})$ & 2.3 & 1.2 \\
\hline Glucose & $70-110(\mathrm{mg} / \mathrm{dL})$ & 76 & 79 \\
\hline Magnesium & $1.4-1.9(\mathrm{mEq} / \mathrm{L})$ & 1.8 & 1.9 \\
\hline Intact-parathyroid hormone & $10-65(\mathrm{pg} / \mathrm{mL})$ & 37 & 48 \\
\hline $1,25(\mathrm{OH}) 2 \mathrm{D} 3$ & $20-60(\mathrm{pg} / \mathrm{mL})$ & 20.8 & 23.6 \\
\hline $25(\mathrm{OH}) \mathrm{D}$ & 9-33.9 (ng/L) & 22.6 & 20.2 \\
\hline Bone-specific alkaline phosphatase & 9.6-35.4 (U/mL) & 95.1 & 100 \\
\hline Osteocalcine & $2.5-13(\mathrm{ng} / \mathrm{mL})$ & 8.5 & 9.6 \\
\hline TRAP-5b & $170-590(\mathrm{mU} / \mathrm{dL})$ & 669 & 988 \\
\hline FGF23 & $<10(\mathrm{pg} / \mathrm{mL})$ & $<10$ & $<10$ \\
\hline $\mathrm{pH}$ & $7.35-7.45$ & 7.36 & 7.35 \\
\hline Bicarbonate ( $\left.\mathrm{HCO}^{-}\right)$ & $22-26(\mathrm{mmol} / \mathrm{L})$ & 18 & 19 \\
\hline eGFR & $90-150(\mathrm{~mL} / \mathrm{min})$ & 71.1 & 63.8 \\
\hline Anion gap & $10-14(\mathrm{mEq} / \mathrm{L})$ & 10 & 14 \\
\hline \multicolumn{4}{|l|}{ Urine } \\
\hline$\overline{\mathbf{p H}}$ & $4.5-7.5$ & 5.3 & 5 \\
\hline Glucose & $<0.1$ (g/day) & 4.9 & 2.1 \\
\hline Protein & $<0.1$ (g/day) & 0.75 & 0.54 \\
\hline Calcium & 40-200 (mg/day) & 62.8 & 23.3 \\
\hline Phosphate & $0.5-0.9$ (g/day) & 2.2 & 0.98 \\
\hline$\beta 2$ microglobuline & $130-329(\mu \mathrm{g} / \mathrm{L})$ & 72,038 & 50,391 \\
\hline Aminoaciduria & minus & plus & plus \\
\hline Tmp/GFR & $0.8-1.3(\%)$ & 0.52 & 0.74 \\
\hline
\end{tabular}

denly occurred without any precipitating cause and then worsened.

On admission, the patient was $158 \mathrm{~cm}$ tall and weighed $63.8 \mathrm{~kg}$. The laboratory data are shown in Table 1.

The findings of generalized aminoaciduria, renal glucosuria, hypophosphatemia, hypouricemia, and proximal tubular metabolic acidosis with a normal anion gap indicated the presence of Fanconi syndrome. Potential causative disorders such as multiple myeloma were excluded. Radiographs of the lower tibial shaft showed narrow radiolucent lines measuring 2 to $4 \mathrm{~mm}$ in width with sclerotic borders, which are called Looser zones and indicate the presence of pseudofractures. These were more prominent in the right leg (Fig. 1a). Bone scintigraphy with ${ }^{99 m}$ Tc-labeled methylene diphosphonate (MDP) demonstrated a high uptake in the bilateral ankles to distal tibiae (including the pseudofractures of the lower tibial shaft), knees, and ribs (Fig. 1b). When the bone mineral density (BMD) was measured by dual-energy X-ray absorptiometry (DEXA), the right forearm and right hip had a BMD that was 2.0 and $2.4 \mathrm{SD}$ below the female mean peak bone mass (T-score), respectively. The serum $\mathrm{p}$ level became less than $2.0 \mathrm{mg} / \mathrm{dL}$ at 20 months after the administration of ADV, while bone pain occurred at 52 months, and bone biopsy was done at 56 months (Fig. 1c).

\section{Case 2}

In September 2012, a 65-year-old Japanese woman was admitted to our hospital for an evaluation of severe pain in the bilateral ankles, knees, and ribs. Hepatitis due to HBV infection had been diagnosed in 1982. Lamivudine was started in 2000, but did not suppress the disease activity, so ADV was added at a dose of $10 \mathrm{mg}$ daily in October 2006. The HBV-DNA polymerase titer became negative in July 2010. In addition to pain of the bilateral hip, ankle, and knee joints, a bilateral femoral neck fracture (Fig. 2a) suddenly occurred without any precipitating cause in June 2011. Bilateral femoral head replacement was performed, and risedronate was started at a dose of $17.5 \mathrm{mg}$ weekly, and it was administered for 14 months. However, her bone pain did not subside.

On admission, the patient was $143 \mathrm{~cm}$ tall and weighed $45.3 \mathrm{~kg}$. The laboratory data are shown in Table 1 . Generalized aminoaciduria, renal glucosuria, hypophosphatemia, hypouricemia, and proximal tubular metabolic acidosis with a normal anion gap indicated a diagnosis of Fanconi syndrome. Possible causative disorders such as multiple myeloma were also excluded in this patient. Radiography did not show a definite pseudofracture pattern, but bone scintigraphy with MDP demonstrated a very high uptake in 


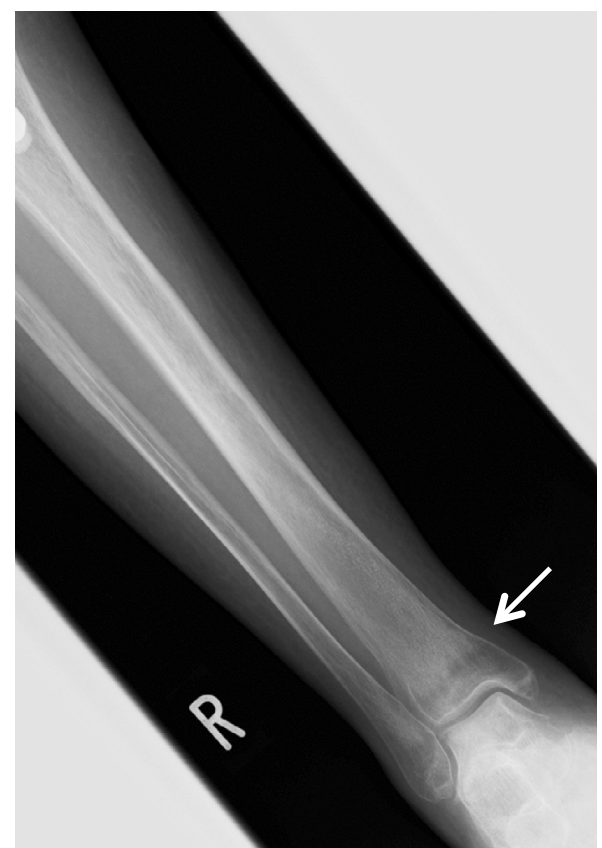

a

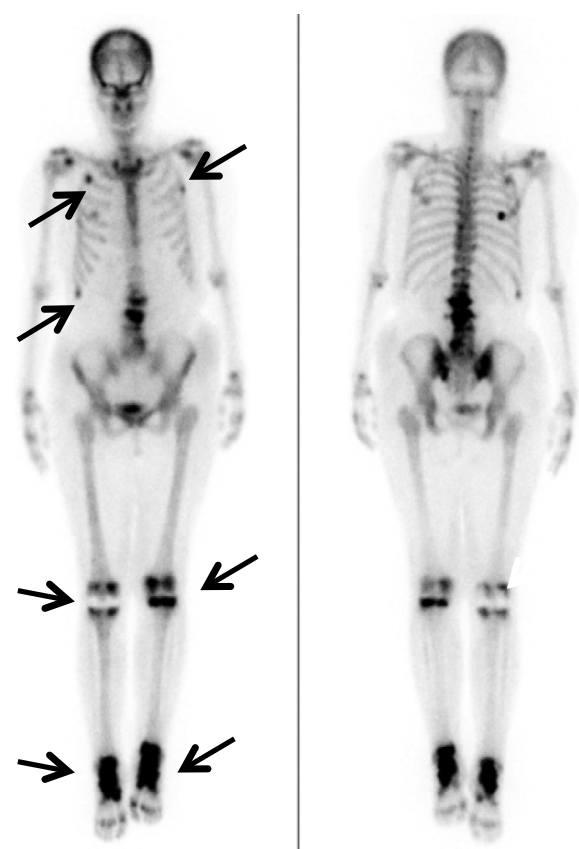

b

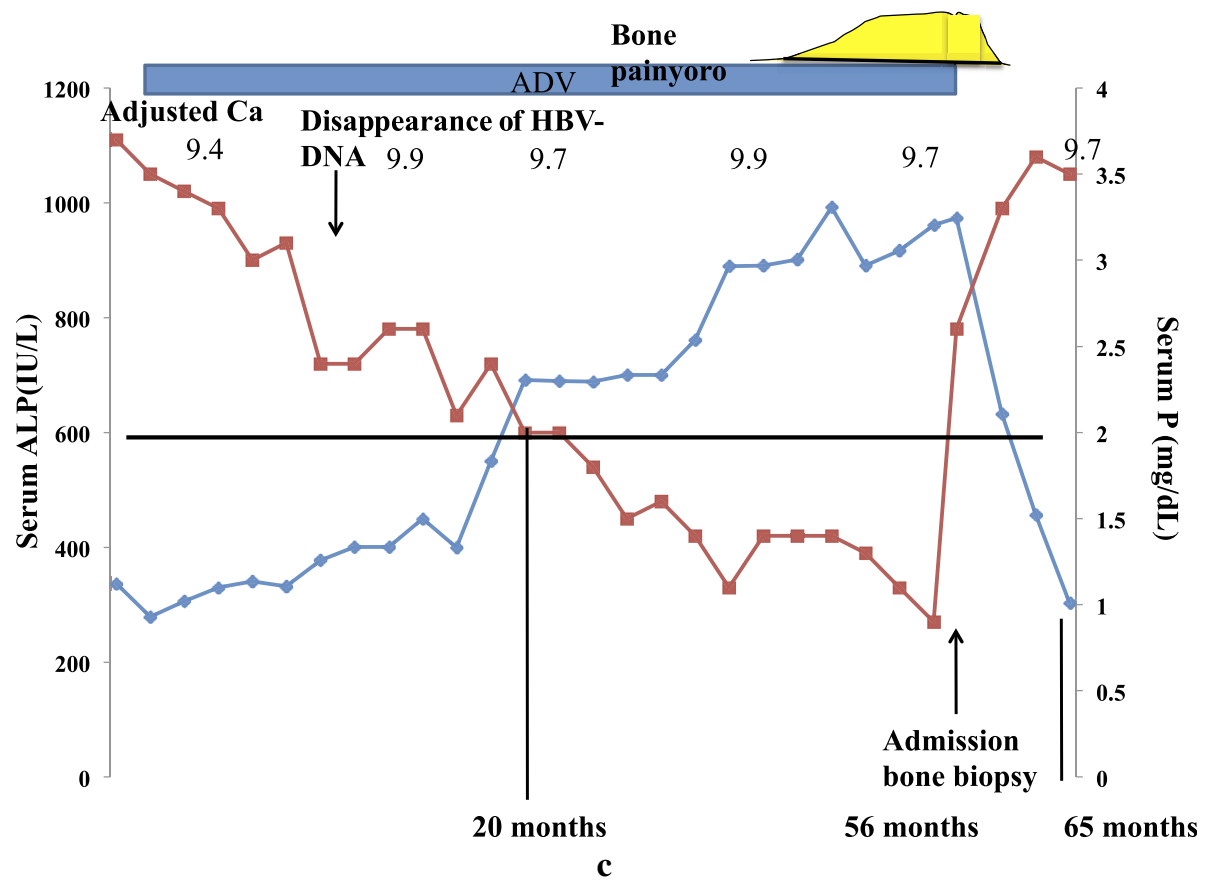

Figure 1. a: Radiograph of the right lower tibial shaft displays narrow radiolucent lines measuring 2 to $4 \mathrm{~mm}$ in width with sclerotic borders (arrow), thus indicating a pseudofracture pattern known as Looser zones. b: Bone scintigraphy with ${ }^{99 \mathrm{~m}}$ Tc-labeled methylene diphosphonate (MDP) demonstrates a high uptake in the bilateral ankles to distal tibiae (including the pseudofracture of the lower tibial shaft), knees, and ribs. c: Clinical course.

the bilateral ankles, knees, hips, and ribs, corresponding to the sites of pain. DEXA showed the BMD of the right forearm to be 3.9 SD below the female mean peak bone mass (T-score). The serum $\mathrm{p}$ level became less than $2.0 \mathrm{mg} / \mathrm{dL}$ at 36 months after the administration of ADV, a bone fracture occurred at 56 months, and a bone biopsy was done at 70 months (Fig. 2b).

\section{Bone histomorphometry}

After obtaining informed consent, double tetracycline labeling was done (with a schedule of 3 days on-7 days off-3 days on-7 days off using doxycycline at $200 \mathrm{mg}$ daily), and a right iliac crest bone biopsy was performed to examine the bone disease in these patients. A histomorphometric analysis was performed using undecalcified thin $(5 \mu \mathrm{m})$ sections of the bone biopsy specimen stained by the Villanueva method. 


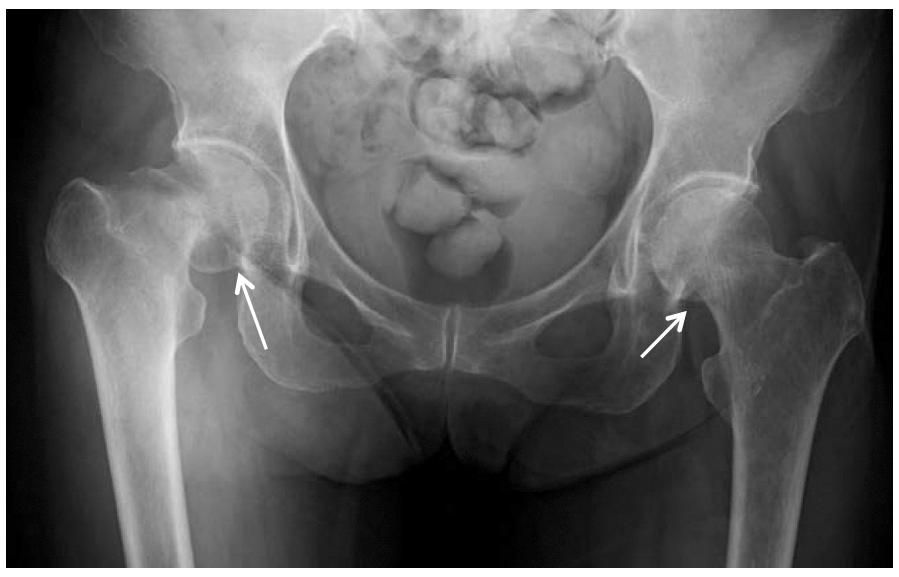

a

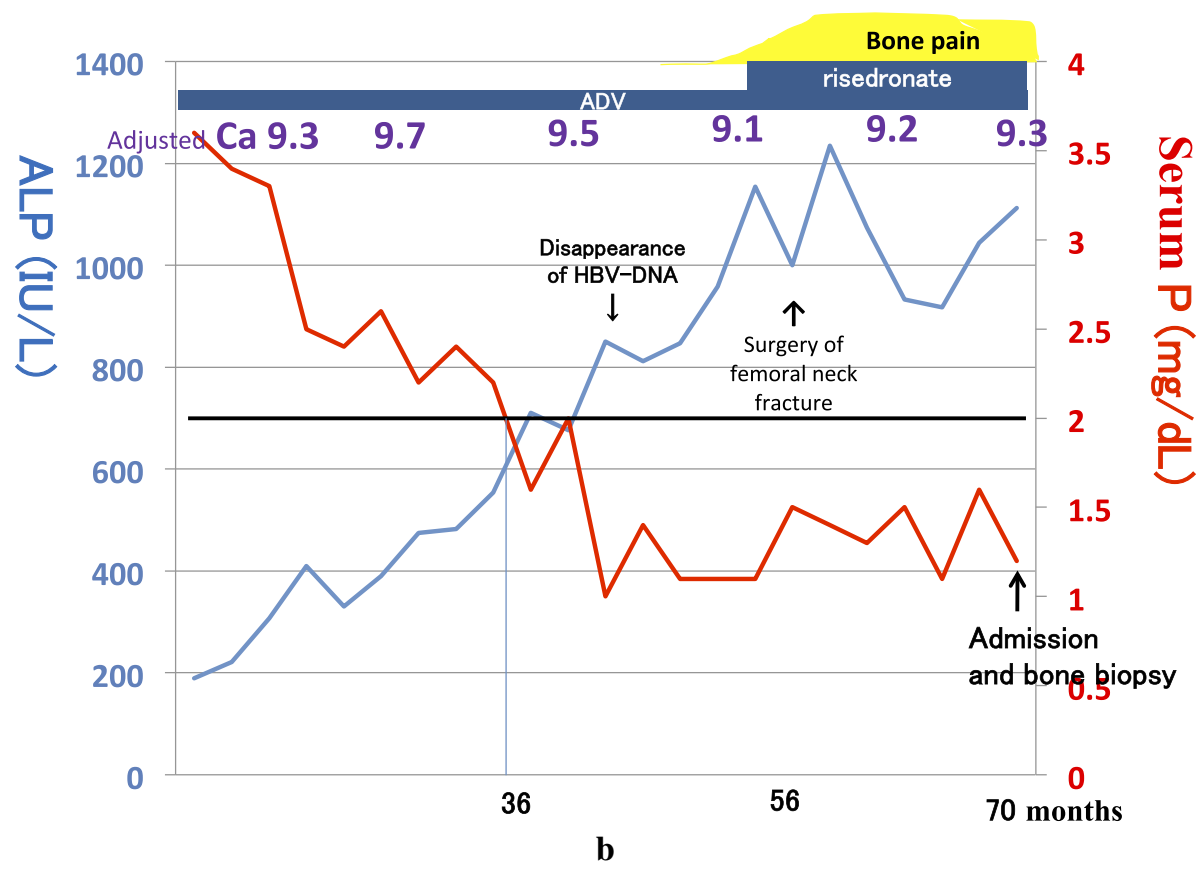

Figure 2. a: A bilateral femoral neck fracture (arrows) occurred suddenly without any precipitating cause. b: Clinical course.

This analysis was carried out by Mrs. Akemi Ito of the Ito Bone Science Institute (Niigata, Japan) (5). The sections were observed with an epifluorescence microscope under ultraviolet light at a magnification of $\times 160$, and the histomorphometric parameters were measured directly using an image analysis system linked to a computer (ASBMR Histomorphometry Nomenclature) (6).

\section{Results}

\section{Case 1}

There was a marked decrease of cancellous bone that had been replaced by adipose tissue, while the cortical bone was preserved (Fig. 3a and Table 2). The cancellous bone adjacent to the cortical bone was evaluated, and it showed features that were diagnostic of osteomalacia (Fig. 3b). There was no tetracycline labeling along most of the trabecular bone surfaces and the osteoid volume had greatly increased [(osteoid volume/ bone volume $) \times 100=18.6 \%$ ]. The ratio of fibrous tissue volume to total volume was $0.0 \%$, while the ratio of total bone volume to total tissue volume had decreased to $11.8 \%$ (normal, $20.8 \pm 1.5 \%$ ) and the ratio of eroded surface to total bone surface had increased to $44.7 \%$ (normal: $5.6 \pm 1.9 \%$ ). The osteoclast numbers near the walls of the resorption cavities had also increased to $1.66 / \mathrm{mm}$.

\section{Case 2}

Almost all of the cancellous bone of case 2 was preserved with trabecular connections, but a reduction of the cortical bone was seen (Fig. 4a). The cancellous bone also showed features that were diagnostic of osteomalacia (Fig. 4b), with no tetracycline labeling along most trabecular bone surfaces and the osteoid volume being greatly increased [(osteoid volume/ bone volume $\times 100=53.8 \%$ ]. The ratio of fibrous tissue volume to total volume was $0.0 \%$, the ratio of total bone volume to total tissue volume had increased to $49.5 \%$ (normal, $20.8 \pm 1.5 \%$ ), and the ratio of eroded surface to total 

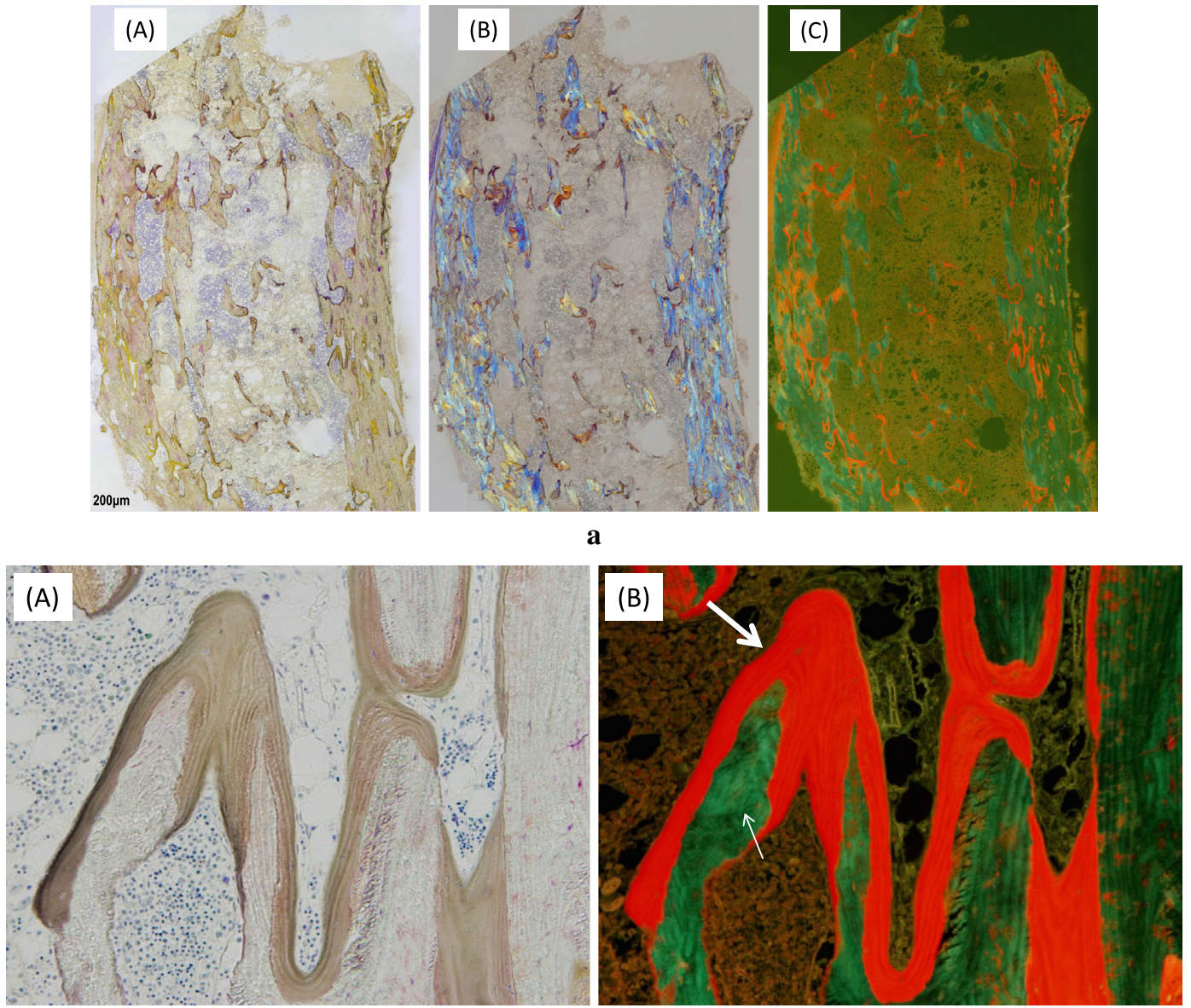

Figure 3. a: Cancellous bone has markedly decreased and has been replaced by adipose tissue, but the cortical bone is preserved (A: natural, B: polarization, $\mathrm{C}$ : fluorescent). $\mathrm{b}$ : Cancellous bone adjacent to the cortical bone shows features of osteomalacia (case 1). The red area shows osteoid (large arrow) and the green area is mineralized bone (small arrow) (A: natural, B: fluorescent).

Table 2. A Histomorphometrical Analysis of Right Iliac Crest.

\begin{tabular}{|c|c|c|c|c|c|c|}
\hline & Bone parameter & Abbreviation & Unit & case 1 & case 2 & normal range \\
\hline \multirow[t]{8}{*}{ Bone volume } & Bone volume/tissue volume & $\mathrm{BV} / \mathrm{TV}$ & $\%$ & 11.8085 & 49.4742 & $19.56 \pm 5.62$ \\
\hline & Trabecular thickness & Tb.Th & $\mu \mathrm{m}$ & 108.8064 & 272.2858 & $131.3 \pm 28.1$ \\
\hline & Wall thickness & W.Th & $\mu \mathrm{m}$ & $\mathrm{NM}$ & $\mathrm{NM}$ & $28.29 \pm 3.74$ \\
\hline & Osteood volume/tissue volume & $\mathrm{OV} / \mathrm{TV}$ & $\%$ & 2.2041 & 26.6383 & $0.36 \pm 0.31$ \\
\hline & Osteoid volume/bone volume & $\mathrm{OB} / \mathrm{BV}$ & $\%$ & 18.6653 & 53.8426 & $1.20 \pm 0.87$ \\
\hline & Osteoid surface/bone surface & OS/BS & $\%$ & 43.4017 & 92.0994 & $14.0 \pm 6.64$ \\
\hline & Osteoid thickness & O.Th & $\mu \mathrm{m}$ & 24.0983 & 79.5337 & $8.31 \pm 1.99$ \\
\hline & Osteoblasts number/bone surface & N.Ob/BS & $\mathrm{N} / \mathrm{mm}$ & 2.8621 & 1.2146 & \\
\hline \multirow[t]{3}{*}{ Resorption } & Eroded surfase/bone surface & $\mathrm{ES} / \mathrm{BS}$ & $\%$ & 44.7544 & 7.2764 & $3.66 \pm 1.69$ \\
\hline & Osteoclasts number/bone surface & N.Oc/BS & $\mathrm{N} / \mathrm{mm}$ & 1.657 & 0.3599 & \\
\hline & Fibrous volume/tissue volume & $\mathrm{Fb} . \mathrm{V} / \mathrm{TV}$ & $\%$ & 0 & 0 & 0 \\
\hline \multirow[t]{6}{*}{ Mineralization } & Mineral apposition rate & MAR & $\mu \mathrm{m} /$ day & 0 & 0 & $0.477 \pm 0.078$ \\
\hline & Double labeled surface/bone surface & $\mathrm{dLS} / \mathrm{BS}$ & $\%$ & 0 & 0 & \\
\hline & Single labeled surface/bone surface & $\mathrm{sLS} / \mathrm{BS}$ & $\%$ & 0 & 0 & \\
\hline & Bone formation rate/bone surface & $\mathrm{BFR} / \mathrm{BS}$ & $\mathrm{mm}^{3} / \mathrm{mm}^{2} /$ year & 0 & 0 & $0.010 \pm 0.008$ \\
\hline & Bone formation rate/bone volume & $\mathrm{BFR} / \mathrm{BV}$ & $\% /$ year & 0 & 0 & $16.2 \pm 12.5$ \\
\hline & Activation frequncy & Acf & N/year & 0 & 0 & \\
\hline
\end{tabular}

NM: Not measured

bone surface was elevated to $7.3 \%$ (normal: $5.6 \pm 1.9 \%$ ). The number of osteoclasts near the walls of the resorption cavities was only $0.35 / \mathrm{mm}$.

On case 2, the osteoid volume had markedly increased, even though total bone volume was preserved in comparison to case 1. 

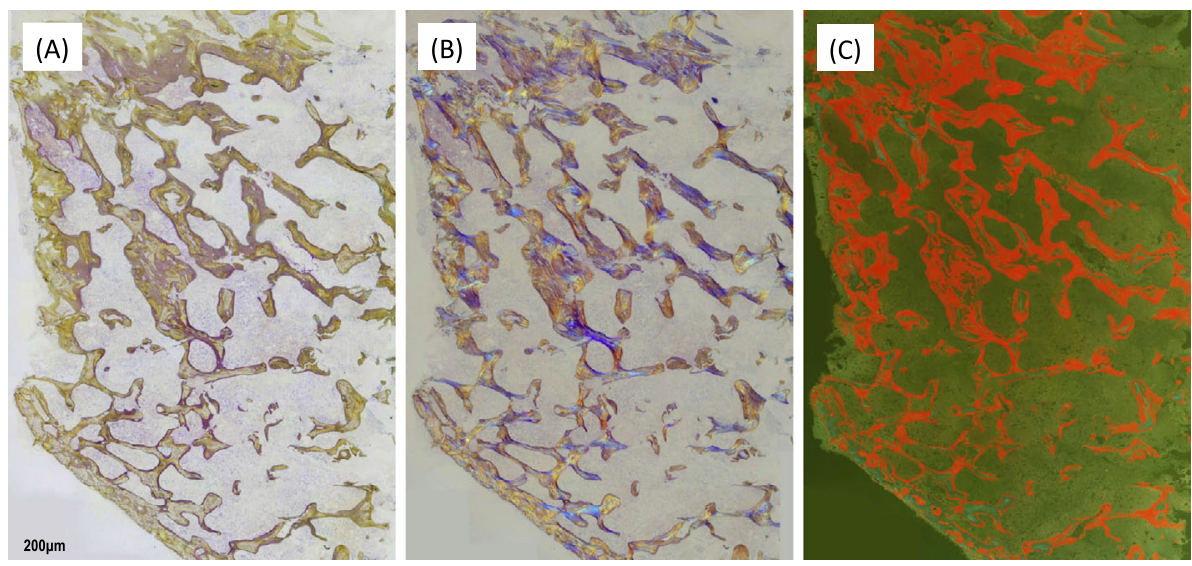

$\mathbf{a}$
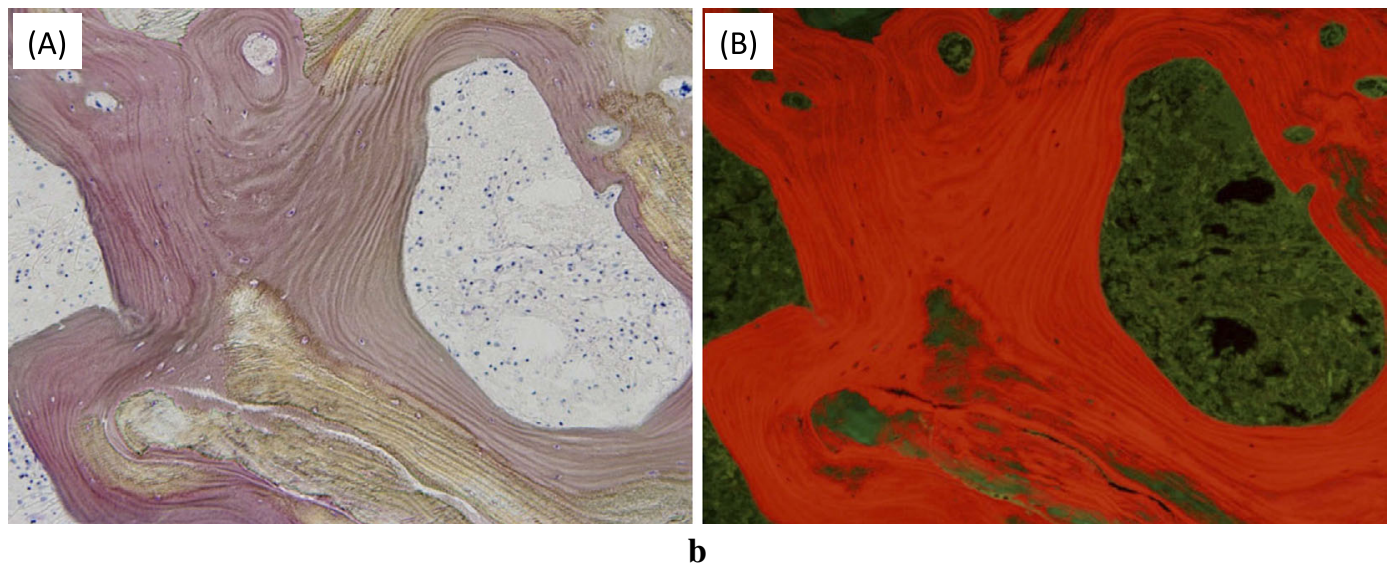

Figure 4. a: In case 2, most cancellous bone is preserved with trabecular connections, but there is a reduction of cortical bone (A: natural, B: polarization, C: fluorescent). b: Cancellous bone also shows changes that are diagnostic of osteomalacia (A: natural, B: fluorescent).

\section{Clinical course}

ADV was therefore changed to entecavir for both patients and a phosphate derivative was administered at a dose of $900 \mathrm{mg}$ daily. In case 2, risedronate was also discontinued. In case 1 , bone pain subsided after 1 month, while laboratory abnormalities (including ALP and bone ALP) returned to normal after 10 months. In case 2 , bone pain subsided after 3 months, and the laboratory data normalized after 12 months.

\section{Discussion}

The diagnosis of osteomalacia requires a bone histomorphometric analysis, and osteomalacia is a disorder characterized by the defective mineralization of newly formed bone matrix that results in an increase in the osteoid volume. It is one of the low-turnover bone diseases, since double tetracycline labeling is absent or very weak along most trabecular bone surfaces, and osteoblasts are usually scant. Therefore, controlling resorption by osteoclasts may contribute to the maintenance of bone volume in osteomalacia (4).

Various other causes have been suggested to cause the onset of osteomalacia in older individuals, including a dietary deficiency of vitamin $\mathrm{D}$ and a decreased synthesis of vitamin D reflecting minimal exposure to sunlight (7). Osteomalacia has also been reported in patients with gastrointestinal disease such as gastrectomy. Patients with a Billroth II gastrectomy were at a greater risk than those with a Billroth I procedure because of the exclusion of the duodenum (8). Drugs such as rifampicin, phenytoin, and phenobarbital also have been reported to induce osteomalacia, since they increase vitamin $\mathrm{D}$ catabolism via hepatic enzyme activation $(9,10)$. Osteomalacia associated with Fanconi syndrome has been thought to result from hypophosphatemia, low circulating 1,25-dihydroxyvitamin $\mathrm{D}$, renal insufficiency, and chronic acidosis due to bicarbonate loss (11). Tumorinduced osteomalacia (TIO) is characterized by hypophosphatemia, an increased urinary loss of phosphate as a result of reduced tubular phosphate reabsorption, and it is caused by fibroblast growth factor 23 (FGF23) (12). There is a report of osteomalacia treated with bisphosphonate (alendronate) without vitamin D. Over the next 21 months, the bone pain worsened, and multiple fractures occurred. Bone histology from the transiliac biopsy samples showed osteomalacia. Bisphosphonate might therefore worsen this disease (13).

In conclusion, we performed a bone first histomorphomet- 
ric analysis in two patients with adefovir-related bone disease. Both patients had a bone histology consistent with osteomalacia, and showed very low turnover bone without new bone formation. The osteoid volume in the patient treated with bisphosphonate was greater than in the other patient. These findings show that bisphosphonate may worsen this disease via interference of the efficient acquisition of hydroxyapatite when this drug is administered without a vitamin D analogue.

The authors state that they have no Conflict of Interest (COI).

\section{Financial Support}

This study was funded by the Okinaka Memorial Institute for Medical Research. We thank Akemi Ito of the Ito bone histomorphometry institute for performing the histomorphometric analysis.

\section{References}

1. Wong T, Girgis CM, Ngu MC, et al. Hypophosphatemic osteomalacia after low-dose adefovir dipivoxil therapy for hepatitis B. J Clin Endocrinol Metab 95: 479-480, 2010.

2. Girgis CM, Wong T, Ngu MC, et al. Hypophosphataemic osteomalacia in patients on adefovir dipivoxil. J Clin Gastroenterol 45: 468-473, 2011.

3. Kim DH, Sung DH, Min YK. Hypophosphatemic osteomalacia induced by low-dose adefovir therapy: focus on manifestations in the skeletal system and literature review. J Bone Mine Metab 31: 240-246, 2013.

4. Ubara Y, Tagami T, Suwabe T, et al. A patient with symptomatic osteomalacia associated with Fanconi syndrome. Mod Rheumatol 15: 207-212, 2005.
5. Tanizawa T, Itoh A, Uchiyama T, Zhang L, Yamamoto N. Changes in cortical width with bone turnover in the three different endosteal envelopes of the ilium in postmenopausal osteoporosis. Bone 25: 493-499, 1999.

6. Parfitt AM, Drezner MK, Glorieux FH, et al. Bone histomorphometry: standardization of nomenclature, symbols, and units. Report of the ASBMR Histomorphometry Nomenclature Committee. J Bone Mineral Res 2: 595-610, 1987.

7. Finch PJ, Ang L, Eastwood JB, Maxwell JD. Clinical and histological spectrum of osteomalacia among Asian in South London. Q J Med 83: 439-448, 1992.

8. Mittal SK, Dash SC, Tiwari SC, Agarwal SK, Saxena S, Fishbane $\mathrm{S}$. Bone histology in patients with nephrotic syndrome and normal renal function. Kidney Int 55: 1912-1919, 1999.

9. Perry W, Erooga MA, Brown J, Stamp TC. Calcium metabolism during rifampicin and isoniazid therapy for tuberculosis. J R Soc Med 75: 533-536, 1982.

10. Bikle DD. Drug-induced osteomalacia. In: Primer on the Metabolic Bone Diseases and Disorders of Mineral Metabolism. 4th ed. Favus MJ, Ed. Lippincott Williams \& Wilkins, Chicago, 1999: 343-346.

11. Clarke BL, Wynne AG, Wilson DM, Fitzpatrick LA. Osteomalacia associated with adult Fanconi's syndrome: clinical and diagnostic features. Clin Endocribol 43: 479-490, 1995.

12. Fukumoto S. Diagnostic modalities for FGF23-producing tumors in patients with tumor-induced osteomalacia. Endocrinol Metab (Seoul) 29: 136-143, 2014.

13. Cundy $T$, Michigami $T$, Tachikawa $K$, et al. Reversible deterioration in hypophosphatasia caused by renal failure with bisphosphonate treatment. J Bone Miner Res 30: 1726-1737, 2015.

The Internal Medicine is an Open Access article distributed under the Creative Commons Attribution-NonCommercial-NoDerivatives 4.0 International License. To view the details of this license, please visit (https://creativecommons.org/licenses/ by-nc-nd/4.0/).

(C) 2016 The Japanese Society of Internal Medicine http://www.naika.or.jp/imonline/index.html 